changing conditions result in dechlorination of the trichlorophenate and an increasing concentration of dioxin.

The easiest and most reliable method of assessing the quantity of dioxin released during the Séveso accident would have been to examine the reactor contents in the wake of the explosion. This was never done. A court order prevented anyone from investigating the reactor contents for fourteen months; all estimates made by the Italian authorities had to be calculated from the concentration of the chemical on exposed surfaces at Séveso. The figure arrived at was 0.5 to $1.5 \mathrm{~kg}$. But the court order could have had more serious consequences. Sambeth believes that it is unlikely that the reactor contents would have changed a great deal in the intervening months between accident and investigation of the reactor; but he concedes that a change is not impossible, and that it could complicate his research programme.

Two further possibilities had also to be studied by Givaudan. The ethylene glycol solvent might have decomposed, generating large quantities of hydrogen; or air introduced into the vessel might have formed peroxides on the reaction surface. Neither of these changes was observed in the laboratory.
With most of the options ruled out, Sambeth is indeed puzzled as to the cause of the Séveso explosion. He says that other chemical companies have been approached for assistance, but none has managed as yet to provide a satisfactory explanation of the events on 10 July. It is Sambeth's belief, in view of his investigations and of the original design of the trichlorophenol reactor, that Givaudan would be correct in considering the accident to have been unforseen, and that the company was not guilty of negligence. It remains to be seen whether the court agrees with this.

Alastair Hay

\title{
European Patent Office poses problems for microbiologists
}

Microbiologists considering patenting a new microbiological process, microbially-produced end product or even a genetically-engineered microorganism, face a maze of patent regulations daunting enough to disccurage all but the most confident. In particular, the requirements of the newest arrival on the international patents scene, the European Patent Office, with regard to 'microbiological' patents, are being strongly opposed by prospective patentees.

The European Patent Office in Munich has been set up under the European Patent Convention to enable patent rights in all European countries to be gained by a single application instead of by separate applications to the national offices. However, prospective patentees, mainly from the pharmaceutical and chemical industries, object that the present Rule 28 of the Convention dealing with microorganisms does not provide sufficient protection for the patentee while the patent is under examination.

Under Rule 28 the applicant must deposit cultures of the microorganisms specified in the patent application (if the microorganism is "not generally available to the public") when the patent is filed. The deposit must be with an approved culture collection to which the public have access. Most national patent laws require deposition of a culture on the grounds that the 'invention' has not been sufficiently described if a culture is not available.

The objection to Rule 28 arises from the conditions, or lack of them, governing the release of the culture while the patent is being examined. As soon as the patent is first published, some 18 months after filing, the culture is available on request to any legally-entitled person who undertakes to use it for experimental purposes only. In some countries, including the USA and
Japan, cultures are not released, or are only released under certain conditions, until the patent is granted. The prospect of a potentially valuable culture falling into the hands of competitors at such an early stage in the application and without any compensation for subsequent commercial misuse, has alarmed the chemical and pharmaceutical industries which have formed an informal association-MICROPATto lobby the EPO for changes in the regulations.

At a recent meeting of industrial microbiologists and patent experts, S. Crespi, Patents Controller of the National Research and Development Corporation, urged participants to keep up the pressure for change. The EPO is at present "receptive" to representations for change, said Crespi. Since there is no obligation to file patents with the EPO rather than the national patent offices the EPO undoubtedly wishes to avoid a boycott by its potential customers.

MICROPAT wants to limit the availability of cultures for which patents have not yet been granted. They have suggested that for residents of the countries specified in the patent application, the culture would be available at the time of first publication (18 months after filing the application) provided there is compensation for any commercial misuse of the culture before the patent is finally granted, which can take several years.

The UK national law does give such retrospective rights. In countries where such protection is not available, the culture should not be released until the second publication (when the patent is granted), as in Japan and the USA. MICROPAT also wants access to cultures by non-residents of the countries covered by the application to be restricted. Their only access should be through an independent resident inter- mediary who would be able to carry out experiments and communicate the results to them.

The requirements of the EPO also pose problems for the culture collections themselves. For the purposes of the EPO an 'approved' collection is one with which the EPO has made a contract. As the regulations stand, an approved collection would then have no right to refuse a culture on the grounds that it was too dangerous or difficult to handle. This has led to no contracts yet being agreed between EPO and the British culture collections -notably the National Collection of Industrial Bacteria-who are at present negotiating with the EPO for such rights of refusal.

Who would bear legal responsibility in the case of accidental loss or damage to the cultures also worries the collections. This will have to be clarified before agreements are signed. Dr I. J. Bousfield drew a distinction between the case of the EPO and the requirements of the Budapest Convention, 1977 (not yet ratified). This provides for a single deposition in a recognised 'International Depository Authority' to be sufficient for a patent to be filed anywhere in the world. In this case however the legal responsibility rests squarely on the governments of the countries concerned.

The requirement to release the culture to any legally-entitled person also raises ethical problems for the culture collections if the organism in question is a potential pathogen, and they are aware that the person requesting it is not competent to deal with it. The National Type Culture Collection, which deals with medically important bacteria, is reluctantly facing the prospect of dealing with 'patentable' microorganisms for the first time, since the Health and Safety at Work Commission require that a culture of any 
potentially pathogenic organism which might be used industrially must be deposited with them.

The difficulty of proving identity between cultures, exaggerated by the propensity of microorganisms to change in culture, poses practical and philosophical problems for patent law. The ability to specify genetic sequences precisely in terms of their nucleotide sequence could provide a basis for criteria of identity, as $\operatorname{Dr} R$. Hill of the National Type Culture Collection pointed out, but the problem of what constitutes a sufficient difference in patent law would still remain.

Patent law has not yet got to grips with the problem of geneticallyengineered bacteria, both in terms of their patentability and of the particular

\section{Sweden's sunny future}

How might Sweden's energy be supplied in the year 2015? A report, 'Solar or uranium-to choose an energy future', shortly to be published by the Secretariat for Future Studies, describes two alternatives. Each costs the same and each gives everyone in the country the material standard of living of today's top $10 \%$ of the population. The uranium alternative would mean 70 nuclear reactors, half of them breeders. Under the solar alternative, energy would come from biomass, solar cells, hydropower, windpower and solar heating.

The assumptions in the report are that the population in 2015 will be the same as it is today-about eight million; that energy demand will be reduced to $80 \%$ of today's in industry (which agrees with the official prognosis for the year 1995), to $50 \%$ of today's in the service sector (transport of people and goods, commerce and government services such as education), and to $70 \%$ of today's for housing (mainly space heating).

Under the solar alternative, $351 \mathrm{TWh}$ would be supplied by biomass and converted to the demand sector by fuel cells, the production of methanol and district heating cogeneration. The energy plantations needed would cover 2.9 million hectares (about 6-7\% of Sweden's total land area), with an average production of $90 \mathrm{MWh}$ per hectare per year. Solar cells would

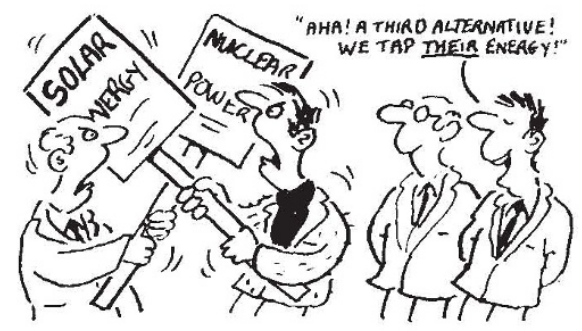

difficultics there might be in storing bacteria whose claim to originality lies in the properties possessed by a plasmid, which in some circumstances could be lost from its bacterial host. What should be patented--the recombinant plasmid itself or the combination of plasmid and bacterium? When will the techniques of genetic manipulation be sufficiently standard and the outcome sufficiently predictable for the product not to be patentable without some further original twist? G. S. A. Szabo, Patents Manager for the Wellcome Foundation, encouraged his audience to test the patent system with applications. As always however it looks as though the chief beneficiaries will be the lawyers.

Eleanor Lawrence

supply a total of $50 \mathrm{TWh}$. Some would be connected directly to their loads; others would be used for the production of methanol; still others for seasonal storage of energy. Hydropower would yield $65 \mathrm{TWh}$, as compared to its present $57 \mathrm{TWh}$ (a limited expansion, taking into account environmentalists' objections to the building of more plants). Windpower would contribute $30 \mathrm{TWh}$ from 3700 units. Solar heating would be mainly used for space heating and would supply $71 \mathrm{TWh}$. The sun shines on Sweden for 1,500-2,000 hours a year $(40 \%$ as much as North Africa), but because practically all of them are between May and September, storage systems would be needed to keep summer's heat for winter. The authors estimate that a 500,000-cubic metre reservoir of water would be able to store enough heat for several apartments in a district heating system.

At the moment, renewable sources provide $24 \%$ of Sweden's energy. Assuming that the first production units in all the renewable-source systems could be operating in 1990 , the report foresees them providing $50 \%$ of the country's energy by the year 2000 and $100 \%$ by 2015 .

The actual setting up of such a system would be far from simple, given the political pressures that exist for expanding nuclear power. Some of the possible snags the authors discuss are their assumptions that the research and development now being done into renewable energy technologies will be successful, and the inevitable clashes over land use. But it was partially to point out the snags of both energy systems that the authors, engineers Peter Steen and Måns Lönnroth and theoretical physicist Thomas Johansson. wrote the report.

\section{Success for unified field theory}

"I think the unification is there and we really have three forces of nature" said Abdus Salam last week. He was referring to a result, a closely guarded secret, announced last Monday (12 June) at the Stanford Linear Acceleraor Center in California, which vindicated the unified field theory of the weak and clectromagnetic interactions developed independently in 1967 and 1968 by himself and Steven Weinberg.

Threc hundred people crammed into the SLAC seminar room to hear the result, announced by $\mathrm{Dr}$ Richard Taylor and his group. Even Salam (of Imperial (ollege, London) and Weinberg (of Harvard) had not been told what the result would be. In the event, their theory was confirmed, there was not a single question on experimental technique, and the experimenters received a standing ovation.

Dr Taylor also lead the group which in the late 1960s had shown that there were tiny, hard objects within protons and neutrons. These are now universally believed to be quarks. In that experiment Taylor had fired high energy electrons at protons and measured their scattering, rather as Rutherford had fired alpha particles at atoms and discovered the nucleus. This time the electrons were polarised-with their intrinsic spin pointing in a fixed direction-but otherwise the experiment was the same.

The polarisation enabled the group to determine if the interaction of electron and proton showed any distinction hetween right and left. The Weinberg-Salam model predicted that it should, and in conjunction with neutrino experiments which had set the scale for the so-called 'parity breaking' between right and left, there was a precise prediction of the amount of parity breaking that should be seen in the SLAC experiments. Just this amount. which comes from interference within the model between the parity-violating weak force and electromagnetism. was observed.

"In a sense a chapter is closed" said Salam. Neutrino experiments had been converging on the Weinberg-Salam model. "The degree of agreement was uncanny". But two atomic physics experiments, measuring the same effect as the SLAC experiment, disagreed with the neutrino results, so all was not roses. These results still stand, but high energy physicists will feel more inclined to accept the rather clean experiment from SLAC, than the ingenious, but complex, experiments from Oxford and Seattle. More about this in News and Views soon.

Robert Walgate 